\title{
Tuning of PID Controller in an Interconnected Power System using Particle Swarm Optimization
}

\author{
Mallipeddi Kavya \\ M.Tech. \\ V R Siddhartha Engineering College (Autonomous)
}

\author{
Gummadi Srinivasa Rao \\ Associate professor \\ V R Siddhartha Engineering College (Autonomous)
}

\begin{abstract}
This paper, deals with tuning of PID controller for the Load Frequency Control (LFC) system of an interconnected power system using Particle Swarm Optimization (PSO). A two area thermal system with governor dead - band nonlinearity and a two area power system with multi-source power generation are considered for study. A two area multi-source power generation system comprises hydro, gas and thermal sources in area-1 and thermal source in area-2. Both the areas are equipped with PID controller. Parameters of these PID controllers are obtained using Particle Swarm Optimization (PSO). The objective function taken into consideration here is Integral Square Error (ISE). A comparative study on tuned values has been presented to confirm effectiveness. ZieglerNichols (Z-N) method is used for tuning of parameters for comparative study. The efficiency of the proposed method is confirmed via wide study using MATLAB/SIMULINK software. The existing LFC systems help out the frequency and tie line power deviations to settle quickly with zero steady state error.
\end{abstract}

\section{General Terms}

Frequency deviation, Tie line power deviation

\section{Keywords}

Load Frequency Control (LFC), Particle Swarm Optimization (PSO), Ziegler-Nichols (Z-N) method, Area Control Error (ACE), PID controller.

\section{INTRODUCTION}

In power systems natural energy is converted into electric energy. They transport electricity to factories and houses to assure all kinds of power needs. It is well known that threephase alternating current (AC) is usually used to transport the electricity. Throughout the transportation, both the active power balance and the reactive power balance must be maintained between generating and utilizing the $\mathrm{AC}$ power [1]. The active power depends on frequency and the reactive power depends on voltage. The most important objective of power system controller is to maintain the uninterrupted balance between electrical generation and varying load demand and the related system losses while system frequency and voltage level are maintained constant. The load variation in the power system influences the quality of power. Thus a control system is essential to cancel the effects of arbitrary load changes and to keep the frequency and voltage at the stable level.
The active power and frequency control is referred as Load Frequency Control (LFC). The objectives of the LFC in interconnected power system is to maintain the frequency of each area and to keep tie-line power flows within the prespecified tolerance by adjusting the output of the high capacity generators when fluctuations occur in load demands.

A typical large - scale power system is composed of several areas of generating units interconnected together and power is exchanged between the utilities. The problem of an interconnected power system is the control of electric energy with supposed system frequency, voltage profile and tie-line power interchanges within their approved limits.

The design of automatic generation controller depends upon different energy source dynamics involved in the AGC of the area. A large number of research papers have been published in the last three decades in which the power system considered for these studies were two area thermal-thermal or hydro-thermal systems But in existent situations each control area may have large number of various sources of power generation such as hydro, thermal, gas, nuclear etc. The various generations are connected by a rigid network that is why the frequency deviations are assumed to be equal in an area [2] [3].

There are many methods available for Load Frequency Control in an interconnected power system. The first proposed control strategy is integral control action to minimize the Area Control Error (ACE). The main drawback of this controller is that the dynamic performance of the system is limited by its integral gain. Despite the potential of modern control techniques with different structure, PID type controller is widely used for solution of LFC problem. PID type controller is not only used for their simplicities, but also due to its success in a large number of industrial applications. In classical methods, such as Ziegler-Nichols and Cohen-Coon, PID controller are tuned based on trial-error approaches and, therefore, they are not capable of providing good robust performance. To attain optimal gains for PID controller, Genetic Algorithm (GA) or Particle Swarm Optimization (PSO) methods were used [4]. According to current research it has found that Genetic Algorithm (GA) has some drawbacks such as the parameters being optimized are highly correlated. They need to run several times to obtain best optimal solution. Also the premature convergence of Genetic Algorithm degrades its performance and reduces its search capability resulting in sub-optimal solutions. To defeat this problem of sub- optimal convergence, powerful computational intelligent evolutionary technique such as Particle Swarm Optimization (PSO) is proposed to optimize the PID gains of controller for the Load Frequency Control (LFC) problem in power systems. 
The objective of this study is to examine the load frequency control and inter area tie-power control problem for a multiarea power system taking into consideration the uncertainties in the parameters of system. An optimal control scheme based particle swarm optimization (PSO) Algorithm method is used for tuning the parameters of this PID controller. The proposed controller is simulated for a two-area power system with governor dead - band nonlinearity and multi-sources power generation. To show effectiveness of proposed method a comparative study is made between Ziegler-Nichols (Z-N) method and Particle Swarm Optimization (PSO) methods.

\section{PID CONTROLLER}

The block diagram of Proportional Integrative Derivative (PID) controller is shown in Fig.1

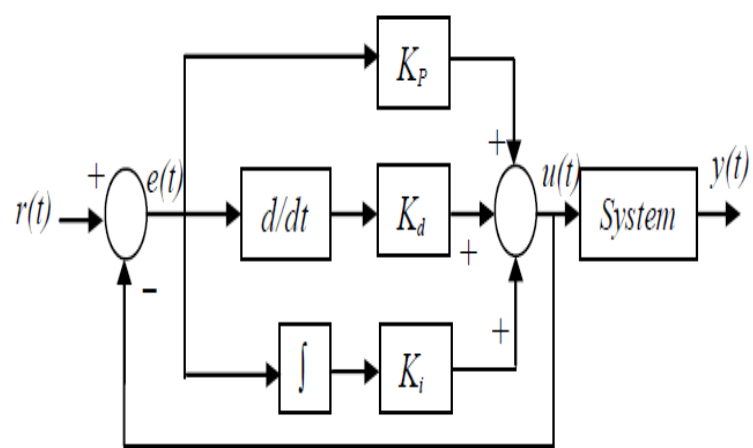

Figure 1: Block diagram of a PID controller

The PID controller improves the transient response so as to reduce error amplitude with each oscillation and then output is finally settled to a final desired value. Improved margin of stability is ensured with PID controllers. The mathematical equation for the PID controller is given as

$$
\begin{aligned}
Y(t)=K_{p} e(t)+ & K_{i} \int_{0}^{t} e(t) d t \\
& +K_{d} \frac{d}{d t} e(t)
\end{aligned}
$$

Where $\mathrm{y}(\mathrm{t})$ is the controller output and $\mathrm{u}(\mathrm{t})$ is the error signal. $\mathrm{K}_{\mathrm{P}}, \mathrm{K}_{\mathrm{I}}$ and $\mathrm{K}_{\mathrm{D}}$ are proportional, integral and derivative gains of the controller [4]. The proportional control $\left(\mathrm{K}_{\mathrm{P}}\right)$ results in decrease of rise time but also results in oscillatory performance. The derivative control $\left(\mathrm{K}_{\mathrm{D}}\right)$ reduces the oscillations by providing proper damping which results in improved transient performance and stability. The $\left(\mathrm{K}_{\mathrm{I}}\right)$ Integral control reduces the steady state error to zero. The primary design goal is to obtain a good load disturbance response by optimally selecting PID controller parameters. The effect of increasing each of the controller parameters $K_{P}$,
$\mathrm{K}_{\mathrm{I}}$ and $\mathrm{K}_{\mathrm{D}}$ can be summarized as in Table 1. Traditionally, the control parameters have been obtained by trial and error approach, which consumes more amount of time in optimizing the choice of gains. To reduce the complexity in tuning PID parameters, Evolutionary computation techniques can be used to solve a wide range of practical problems including optimization and design of PID gains.

Table 1: It Shows the Effect of Increasing Each of the Controller Parameters

\begin{tabular}{|c|c|c|c|c|}
\hline Response & $\begin{array}{c}\text { Rise } \\
\text { Time }\end{array}$ & $\begin{array}{c}\text { Over- } \\
\text { shoot }\end{array}$ & $\begin{array}{c}\text { Settling } \\
\text { Time }\end{array}$ & $\begin{array}{c}\text { Steady } \\
\text { State } \\
\text { Error }\end{array}$ \\
\hline $\mathrm{K}_{\mathrm{P}}$ & Decrease & Increase & $\begin{array}{c}\text { Minor } \\
\text { Change }\end{array}$ & Decrease \\
\hline $\mathrm{K}_{\mathrm{I}}$ & Decrease & Increase & Increase & remove \\
\hline $\mathrm{K}_{\mathrm{D}}$ & $\begin{array}{c}\text { Minor } \\
\text { Change }\end{array}$ & Decrease & Decrease & $\begin{array}{c}\text { Minor } \\
\text { Change }\end{array}$ \\
\hline
\end{tabular}

\section{SYSTEMS UNDER STUDY \\ 3.1 A two area thermal system with governor dead - band nonlinearity}

A two area thermal system with governor dead - band nonlinearity is taken for LFC analysis. For an interconnected system, each area connected to others via tie line which is the basis for power exchange between them. When there is change in power in area one, that will be met by the increase in generation in all the areas associated with a change in the tie line power and a reduction in frequency. But the normal operating state of the power system is that the demand of each area will be satisfied at a normal frequency and each area will absorb its own load changes. There will be area control error (ACE) for each area and this area will try to reduce its own ACE to zero. The ACE of each area is the linear combination of the frequency and tie line error, i.e. $\mathrm{ACE}=$ Frequency error + Tie line error. The transfer function model of two area nonreheat thermal power system is shown in figure. 2 and the system data is represented in Table 2.

Table 2: System Data

\begin{tabular}{|c|c|}
\hline Parameters & values \\
\hline $\mathrm{Tg}$ (governor time constant) & $0.2 \mathrm{~s}$ \\
\hline $\mathrm{Tt}$ (Turbine time constant) & $0.3 \mathrm{~s}$ \\
\hline $\mathrm{Kp}$ (load model gain) & $120 \mathrm{~Hz} / \mathrm{pu} \mathrm{MW}$ \\
\hline $\mathrm{Tp}($ load time constant) & $20 \mathrm{~s}$ \\
\hline $\mathrm{T} 1,2($ Synchronizing coefficient) & $0.0707 \mathrm{MW} / \mathrm{rad}$ \\
\hline $\mathrm{B}$ (Frequency bias factors) & $0.425 \mathrm{pu} \mathrm{MW} / \mathrm{Hz}$ \\
\hline $\mathrm{R} 1,2($ Governor Speed Regulation) & $2.4 \mathrm{~Hz} / \mathrm{pu} \mathrm{Mw}$ \\
\hline
\end{tabular}




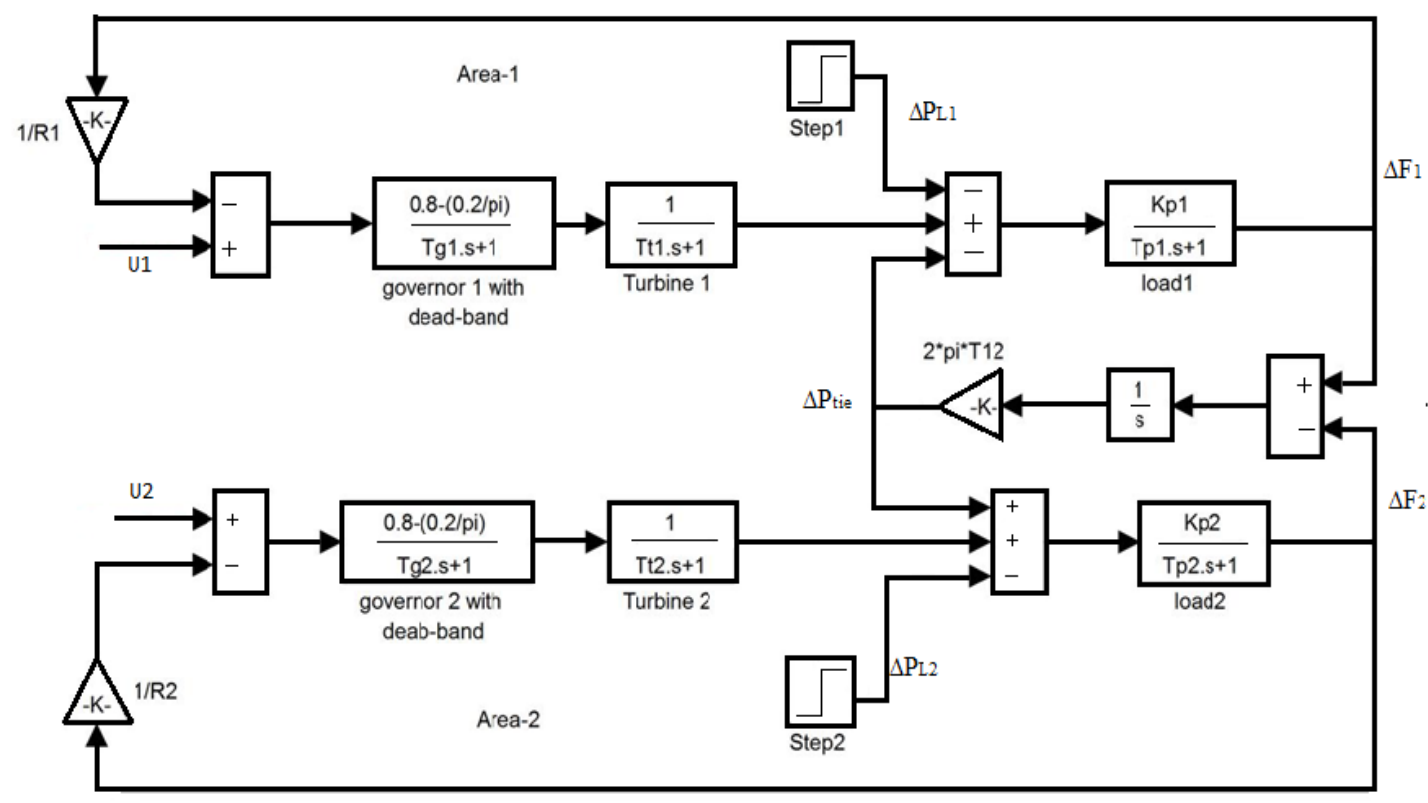

Figure 2: Block Diagram of the Two Area Interconnected Power System with Governor Dead-Band

To make the examination reasonable one, the governor dead band is considered in this model which make the system nonlinear. A governor dead band is defined as the total magnitude of a sustained speed change where there is no change in valve position of the turbine. The governor dead band non-linearity tends to produce a continuous sinusoidal oscillation of natural period of about $\mathrm{T}_{0}=2 \mathrm{~s}$. The transfer function of governor with non-linearity [5].

$$
G(s)=\frac{[0.8-(0.2 / \pi)]}{s T_{g}+1}
$$

\subsection{A two area power system with multi - source power generation}

Figure 3 represents the complete transfer function block diagram of an area with various sources of power generation namely thermal, hydro and gas. A two area multi-source power generation system comprises hydro, gas and thermal sources in area-1 and thermal source in area- 2 is shown in Figure 4. Under normal operating conditions there is no inequality between generation and load.

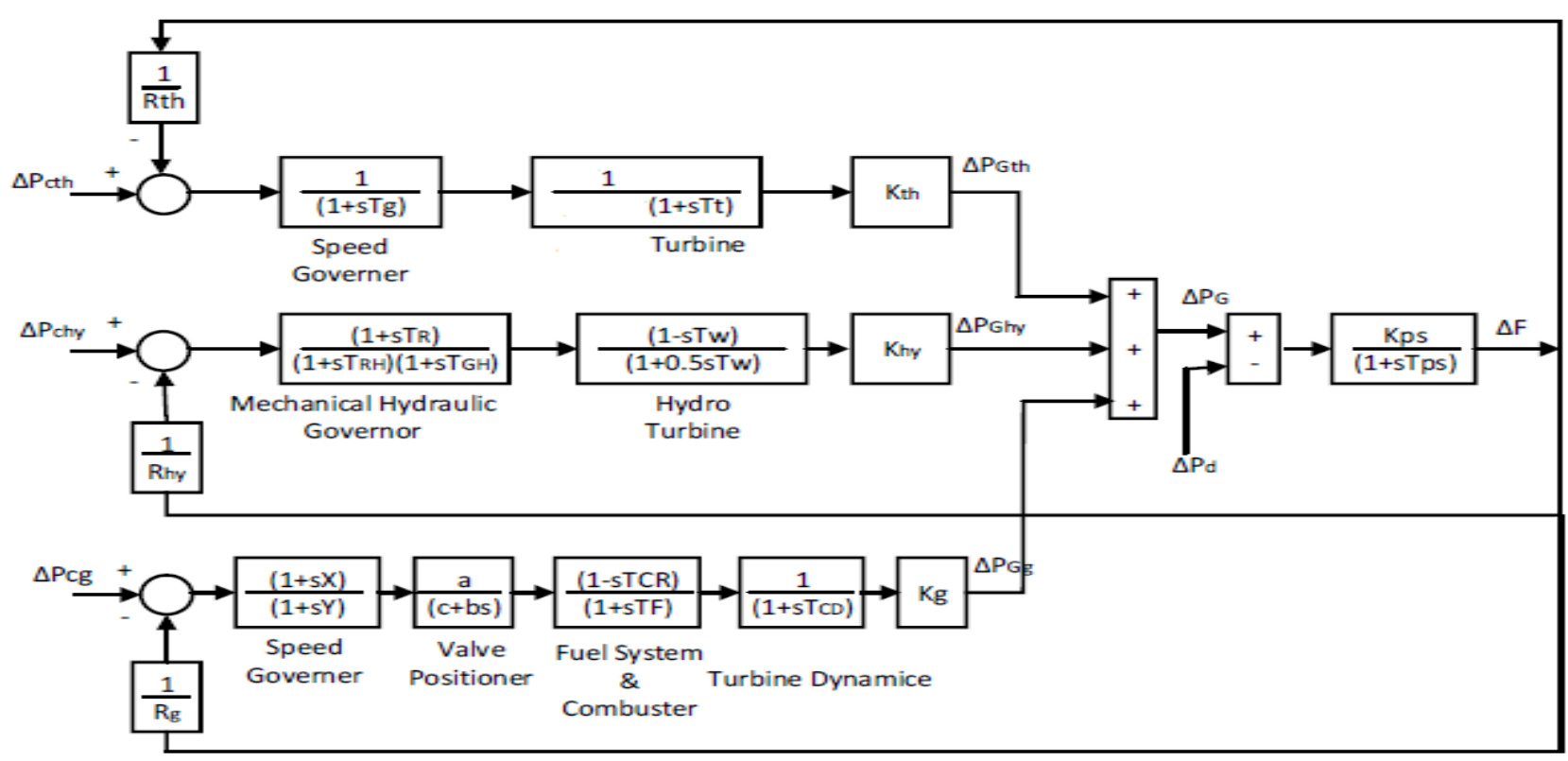

Figure 3: Transfer Function Block Diagram of an Area Having Power Generation from Hydro, Thermal and Gas Sources 


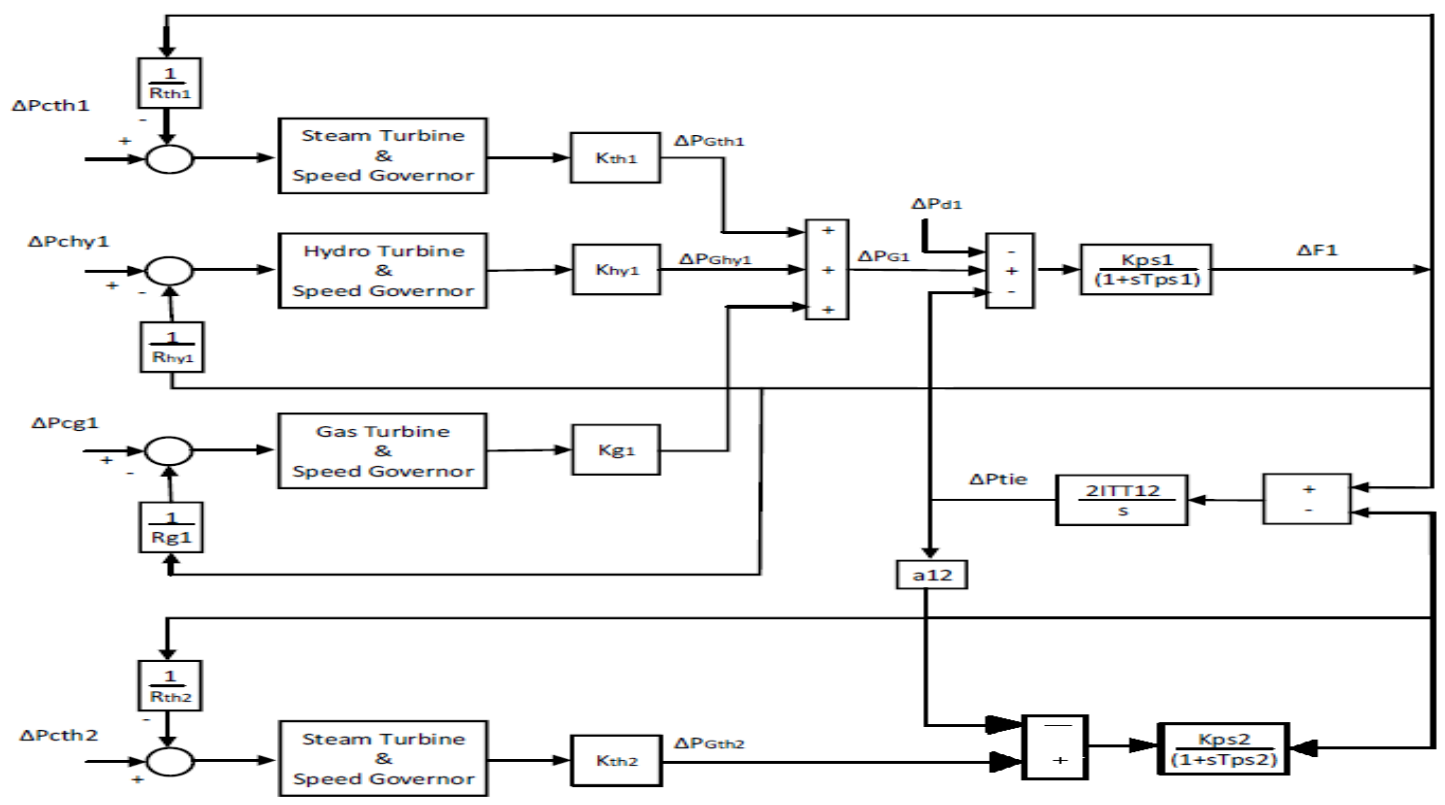

Figure 4: Block Diagram of a Two Area Power System with multi-sources

The dynamics of non-reheat thermal, hydro and gas based units are taken from the literature [6-11] which are referred by most of the researchers for LFC study. The system data of a two area power system with multi-sources is represented in Table 3 . The total generation in area- 1 and area- 2 are given by:

$$
\begin{gathered}
\mathrm{P}_{\mathrm{G} 1}=\mathrm{P}_{\mathrm{Gth} 1}+\mathrm{P}_{\mathrm{Ghy} 1}+\mathrm{P}_{\mathrm{Gg} 1} \\
\mathrm{P}_{\mathrm{G} 2}=\mathrm{P}_{\mathrm{Gth} 2}
\end{gathered}
$$

Where

$\mathrm{P}_{\mathrm{Gth} 2}=\mathrm{K}_{\mathrm{th} 2} \mathrm{P}_{\mathrm{G} 2}$

$\mathrm{P}_{\mathrm{Gthl}}=\mathrm{K}_{\mathrm{th} 1} \mathrm{P}_{\mathrm{G} 1}, \quad \mathrm{P}_{\mathrm{Ghyl}}=\mathrm{K}_{\mathrm{hy} 1} \mathrm{P}_{\mathrm{G} 1}, \quad \mathrm{P}_{\mathrm{Gg} 1}=\mathrm{K}_{\mathrm{g} 1} \mathrm{P}_{\mathrm{G} 1} \quad$ and

$\mathrm{K}_{\mathrm{th}}, \mathrm{K}_{\mathrm{hy}}$ and $\mathrm{K}_{\mathrm{g}}$ represent the share of the power generation by thermal, hydro and gas sources respectively to the total power generation. From Eqns. (3) and (4), under nominal generation and loading, $\mathrm{PG}^{0}=\mathrm{PL}^{0}=1.0 \mathrm{pu}$, we have

$$
\begin{gathered}
\mathrm{K}_{\mathrm{th} 1}+\mathrm{K}_{\mathrm{hy} 1}+\mathrm{K}_{\mathrm{g} 1}=1 \\
\mathrm{~K}_{\mathrm{th} 2}=1
\end{gathered}
$$

Table 3: Data of a system having multi-sources

\begin{tabular}{|c|c|}
\hline Parameters & values \\
\hline Steam turbine: & \\
\hline Speed governor time constant $\left(\mathrm{T}_{\mathrm{sg}}\right)$ & $0.06 \mathrm{~s}$ \\
\hline Turbine time constant $\left(\mathrm{T}_{\mathrm{T}}\right)$ & $0.3 \mathrm{~s}$ \\
\hline Speed governor regulation parameter $\left(\mathrm{R}_{\mathrm{TH}}\right)$ & $2.4 \mathrm{HZ} / \mathrm{pu} \mathrm{MW}$ \\
\hline Hydro turbine: & \\
\hline Speed governor time constant $\left(\mathrm{T}_{\mathrm{RS}}\right)$ & $5 \mathrm{~s}$ \\
\hline Transient droop time constant $\left(\mathrm{T}_{\mathrm{RH}}\right)$ & $28.75 \mathrm{~s}$ \\
\hline Main servo time constant $\left(\mathrm{T}_{\mathrm{GH}}\right)$ & $0.2 \mathrm{~s}$ \\
\hline Water time constant $\left(\mathrm{T}_{\mathrm{W}}\right)$ & $1.1 \mathrm{~s}$ \\
\hline Speed governor regulation parameter $\left(\mathrm{R}_{\mathrm{HY}}\right)$ & $2.4 \mathrm{HZ} / \mathrm{pu} \mathrm{MW}$ \\
\hline Gas turbine: & \\
\hline
\end{tabular}

\begin{tabular}{|c|c|}
\hline Speed governor & \\
lead time constants $\left(\mathrm{X}_{\mathrm{G}}\right)$ & $0.6 \mathrm{~s}$ \\
lag time constants $\left(\mathrm{Y}_{\mathrm{G}}\right)$ & $1 \mathrm{~s}$ \\
\hline Valve position constants & \\
$\left(\mathrm{b}_{\mathrm{g}}\right)$ & $0.05 \mathrm{~s}$ \\
$\left(\mathrm{c}_{\mathrm{g}}\right)$ & 1 \\
\hline Fuel time constants $\left(\mathrm{T}_{\mathrm{F}}\right)$ & $0.23 \mathrm{~s}$ \\
\hline Combustion reaction time delay $\left(\mathrm{T}_{\mathrm{CR}}\right)$ & $0.01 \mathrm{~s}$ \\
\hline Compressor discharge volume time constant & $0.2 \mathrm{~s}$ \\
\hline Speed governor regulation parameter $\left(\mathrm{R}_{\mathrm{G}}\right)$ & $2.4 \mathrm{HZ} / \mathrm{pu} \mathrm{MW}$ \\
\hline Power system: & \\
\hline Frequency bias constants $(\mathrm{B} 1, \mathrm{~B} 2)$ & 0.4312 \\
\hline $\mathrm{a}_{12}$ & -1 \\
\hline load model gain $(\mathrm{Kps})$ & $68.96554 \mathrm{HZ} / \mathrm{pu}$ \\
& $\mathrm{MW}$ \\
\hline load time constant $(\mathrm{Tps})$ & $11.49 \mathrm{~s}$ \\
\hline
\end{tabular}

\section{DEFINING OBJECTIVE FUNCTION}

The control configuration for multi area power system is depicted in fig. 5. The control strategy depends up on tie-line bias control. The error input to the controllers are the respective area control errors (ACE) given by

$$
\mathrm{ACEi}=\Delta \mathrm{Ptie}, \mathrm{I}+\mathrm{Bi} \Delta \mathrm{Fi}
$$

Control input to the power system is obtained by use of PID controller together with the area control errors ACE1 and ACE2. The control input of the power system u1 and $\mathrm{u} 2$ are the output of the controllers and these are obtained as

$$
U_{i}=K_{P, i} A C E_{i}+K_{I, i} \int A C E_{i} d t+K_{D, i} \frac{d\left(A C E_{i}\right)}{d t}
$$


Now a performance index can be defined by adding the sum of squares of cumulative errors in ACE, hence based on area control error a performance index $\mathrm{J}$ can be defined as [12]:

$$
\mathrm{J}=\mathrm{ISE}=\int_{0}^{\infty} \sum_{\mathrm{i}=0}^{2}\left(\mathrm{ACE}_{\mathrm{i}}\right)^{2} \mathrm{dt}
$$

Based on this performance index J optimization Problem can be sated as:

Minimize J

Subjected to:

$K_{P, i}^{\min } \leq K_{P, i} \leq K_{P, i}^{\max }$

$K_{I, i}^{\min } \leq K_{I, i} \leq K_{I, i}^{\max }$

$K_{D, i}^{\min } \leq K_{D, i} \leq K_{D, i}^{\max }$

Where $\mathrm{K}_{\mathrm{P}, \mathrm{i}}, \mathrm{K}_{\mathrm{I}, \mathrm{i}}$ and $\mathrm{K}_{\mathrm{D}, \mathrm{i}}$ are PID controller parameters of $\mathrm{i}^{\text {th }}$ area.

\section{TUNING METHODS}

\subsection{Ziegler-Nichols (Z-N) closed-loop \\ tuning method}

In Ziegler-Nichols (Z-N) tuning rule based on the transient response characteristics of a given plant we can determine the values of Proportional gain $\left(\mathrm{K}_{\mathrm{P}}\right)$, Integral time $\left(\mathrm{T}_{\mathrm{I}}\right)$ and Derivative time $\left(\mathrm{T}_{\mathrm{D}}\right)$. The Ziegler-Nichols $(\mathrm{Z}-\mathrm{N})$ closed -loop tuning method allow to use the ultimate gain value $\left(\mathrm{K}_{\mathrm{u}}\right)$ and ultimate period of oscillations $\left(\mathrm{T}_{\mathrm{u}}\right)$ to calculate the parameters of PID controller [13].

Procedure used in $\mathrm{Z}-\mathrm{N}$ method to find the parameters:

1. Remove the integral and derivative action (set $\mathrm{K}_{\mathrm{I}}$ and $\mathrm{K}_{\mathrm{D}}$ to zero).

2. Create small disturbance in the loop by changing the set point. Adjust the proportional gain until the oscillations have constant amplitude.

3. Record the Critical gain value $\left(\mathrm{K}_{\mathrm{U}}\right)$ and critical period $\left(\mathrm{T}_{\mathrm{U}}\right)$

4. Put these values in to Ziegler-Nichols (Z-N) closed loop equations and determine the controller parameters.

Table 4: Ziegler-Nichols tuning rule

\begin{tabular}{|c|c|c|c|}
\hline $\begin{array}{c}\text { Type of } \\
\text { controller }\end{array}$ & $\mathrm{K}_{\mathrm{P}}$ & $\mathrm{T}_{\mathrm{I}}$ & $\mathrm{T}_{\mathrm{D}}$ \\
\hline $\mathrm{P}$ & $0.5 \mathrm{~K}_{\mathrm{U}}$ & $\infty$ & 0 \\
\hline $\mathrm{PI}$ & $0.45 \mathrm{~K}_{\mathrm{U}}$ & $(1 / 1.2) \mathrm{T}_{\mathrm{U}}$ & 0 \\
\hline $\mathrm{PID}$ & $0.6 \mathrm{~K}_{\mathrm{U}}$ & $0.5 \mathrm{~T}_{\mathrm{U}}$ & $0.125 \mathrm{~T}_{\mathrm{U}}$ \\
\hline
\end{tabular}

Notice that the PID controller tuned by the Ziegler-Nichols $(\mathrm{Z}-\mathrm{N})$ rule gives

$$
G_{c}(s)=K_{P}\left(1+\frac{1}{T_{I} s}+T_{D} s\right)
$$

\subsection{Particle Swarm Optimization (PSO)}

Particle Swarm Optimization (PSO) is an evolutionary computational method developed by Kennedy and Eberhart in 1995. It is developed from swarm intelligence and is based on the research of bird and fish flock movement behavior. The Particle swarm optimization algorithm is a multi-agent parallel search technique which maintains a swarm of particles and each particle represents a potential solution in the swarm. All particles fly through a multidimensional search space where each particle is adjusting its position according to its own experience and neighbor's experience.

Each particle keeps track of its coordinates in the solution space which are associated with the best solution (fitness) that has achieved so far by that particle. This value is called personal best, pbest. Another best value that is tracked by the PSO is the best value obtained so far by any particle in the neighborhood of that particle. This value is called gbest. The basic concept of PSO lies in accelerating each particle toward its pbest and the gbest locations, with a random weighted acceleration at each time step as shown in Fig.5

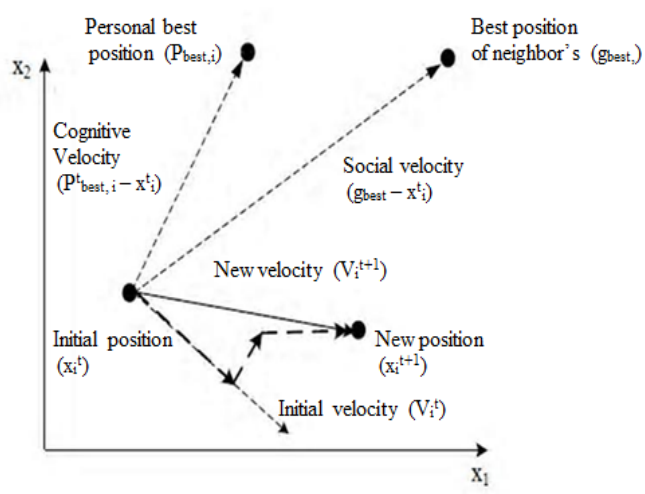

Figure 5: Concept of searching mechanism of PSO

After finding the $\mathrm{p}_{\text {best }}$ and $\mathrm{g}_{\text {best }}$, the particle updates its velocity and positions with following equations

$$
\begin{gathered}
V_{i j}^{t+1}=W V_{i j}^{t}+C_{1} r_{1 j}^{t}\left[P_{\text {best }, i}^{t}-X_{i j}^{t}\right]+C_{2} r_{2 j}^{t}\left[G_{\text {best }, i}-X_{i j}^{t}\right] \\
X_{i j}^{t+1}=X_{i j}^{t}+V_{i j}^{t+1}
\end{gathered}
$$

Where $\mathrm{V}_{\mathrm{ij}}^{\mathrm{t}+1}$ and $\mathrm{X}_{\mathrm{ij}}^{\mathrm{t}+1}$ are the velocity and position of $i^{\text {th }}$ particle in dimension $\mathrm{j}$ at time $\mathrm{t}+1 . \mathrm{C}_{1}$ and $\mathrm{C}_{2}$ are two position constants called acceleration constants. $r_{1}$ and $r_{2}$ are two different random numbers in the range 0 to1. The inertia weight $w$ keeps the movement inertial for the particle. It describes influence of the previous velocity to the current velocity, which means make the algorithm have the trend to extend the search space and have the ability to explore the new district, and there is the function to adjust the rate of velocity of particle. Linear variety of the ' $w$ ' is

$$
\mathrm{W}=\frac{\text { MAXITER }- \text { ITER }}{\text { MAXITER }}
$$

Where, $\mathrm{w}$-is the inertia weighting factor.

ITER $=$ current number of iteration .

MAX ITER =maximum number of iterations. 
There are three terms in velocity equation

1. $\mathrm{W}^{*} \mathrm{~V}_{\mathrm{ij}}^{\mathrm{t}}$ is called inertia component that provides a memory of the previous flight direction that means movement in the immediate past.

2. $\mathrm{C}_{1} \mathrm{r}_{1 \mathrm{j}}^{\mathrm{t}}\left[\mathrm{P}_{\text {best } \mathrm{i}}^{\mathrm{t}}-\mathrm{X}_{\mathrm{ij}}^{\mathrm{t}}\right]$ is called cognitive component. This component looks like an individual memory of the position that was best for the particle.

3. $\mathrm{C}_{2} \mathrm{r}_{2 \mathrm{j}}^{\mathrm{t}}\left[\mathrm{G}_{\mathrm{best}, \mathrm{i}}-\mathrm{X}_{\mathrm{ij}}^{\mathrm{t}}\right]$ is called social component. The effect of this component is each particle fly towards the best position found by the neighbourhood particles.

The flowchart for particle swarm optimization is shown in Figure 6.

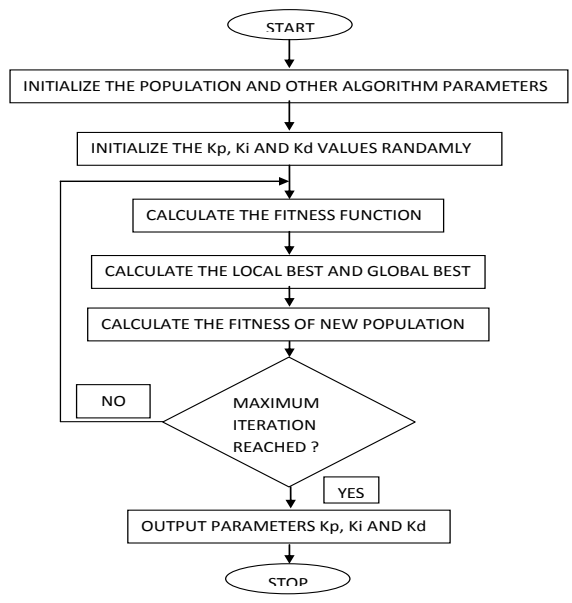

Figure.6 Flowchart of Particle Swarm Optimization (PSO)

\section{SIMULATION RESULTS}

A two area thermal system with governor dead - band nonlinearity and two area power system with multi-source power generation are considered for study. Simulation model of the proposed system with PSO-PID controller is shown in Figures 7.

\subsection{Simulation studies of a two area}

\section{thermal system with governor dead - band}

Simulation is carried out with $1 \%$ step load perturbation in area-1.For comparison the PID controller was tuned using conventional Ziegler-Nichols tuning rule based on critical gain $K_{u}$ and critical period $T_{u}$. Value of $K_{u}$ and $T_{u}$ were calculated from the sustained oscillations of the output by employing only proportional controller. The values obtained after simulation run are critical gain $\mathrm{K}_{\mathrm{u}}=0.09$ and critical period $T_{u}=2$ sec. After replacing critical gain $K_{u}$ and critical period $\mathrm{T}_{\mathrm{u}}$ in Ziegler-Nichols (Z-N) closed loop equations shown in Table. 4 we have $\mathrm{G}_{\mathrm{c}}(\mathrm{s})=0.054+(1 / \mathrm{s})+0.25$. The minimum value of the $J$ is 0.0143 .

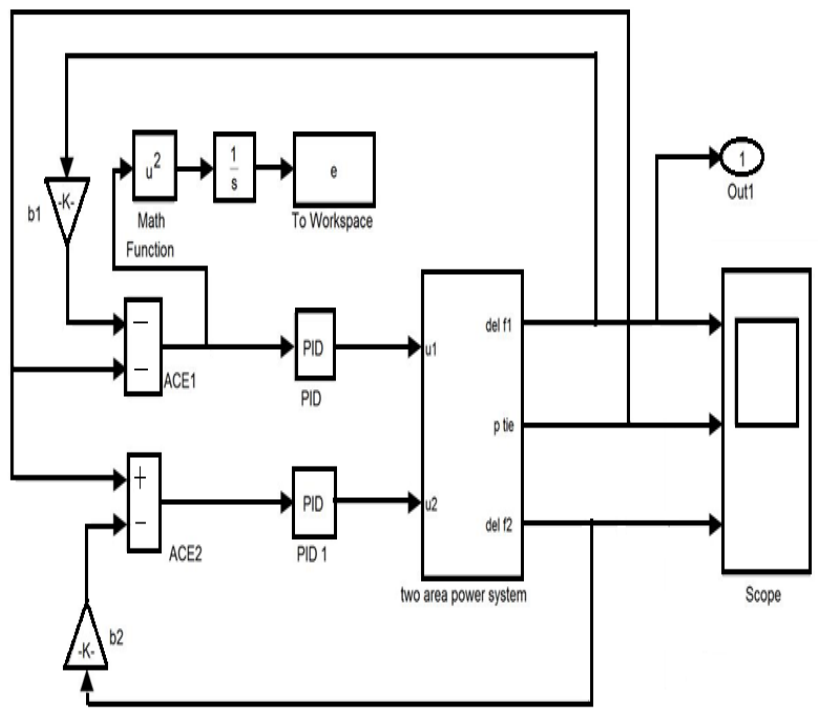

Figure.7 Simulation module used in PSO-based tuning of PID controller for LFC control

The MATLAB code based on PSO algorithm has been run in MATALB Environment. PSO parameters taken for optimizations are: Population size $=50$, Maximum number of iterations $=50, c l=2.5 ; c 2=2.5$ and simulation time $=20 \mathrm{~s}$. The minimum value of the $J$ is 0.0127 . The optimized controller gains obtained are shown in Table 5.

Table 5: Optimized values of PID controller parameters

\begin{tabular}{|c|c|c|c|}
\hline METHOD & $\mathrm{K}_{\mathrm{P}}$ & $\mathrm{K}_{\mathrm{I}}$ & $\mathrm{K}_{\mathrm{D}}$ \\
\hline Z-N Method & 0.054 & 1 & 0.25 \\
\hline PSO-PID & 0.0689 & 0.75 & 0.4508 \\
\hline
\end{tabular}

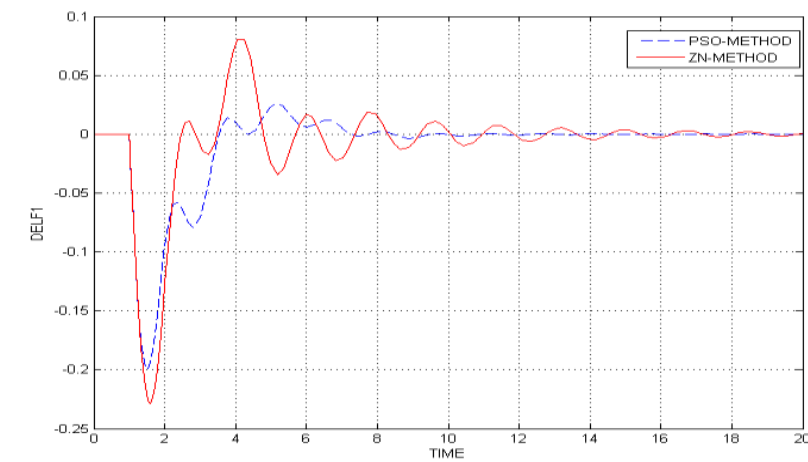

Figure.8 Frequency deviation in area-1 due to step change in area-1 


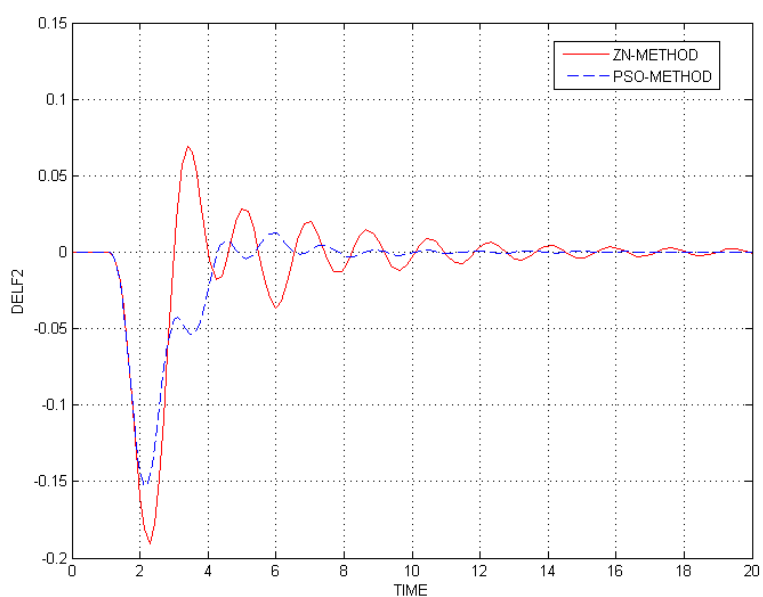

Figure.9 Frequency deviation in area-2 due to step change in area-1

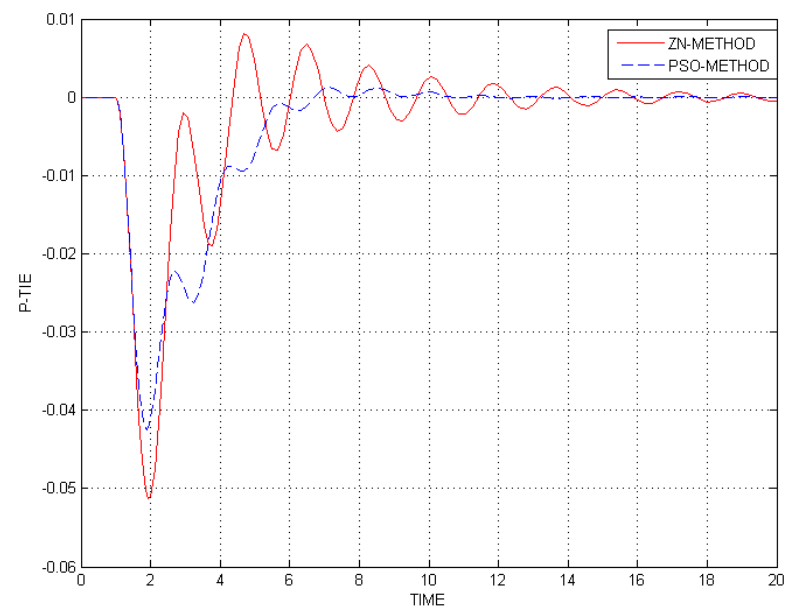

Figure.10 Tie line power deviation due to step change in area-1

The dynamic responses of a two area thermal system with governor dead-band nonlinearities are shown in the figures 810.The frequency deviation responses of control area- 1 and area-2 are shown in figure 8 and 9, respectively. The tie-line power deviation is shown in figure 10. It is observed that control frequency deviation in area-1and area- 2 and tie line power deviation settles quickly in PSO-PID method when compared with conventional (Z-N) method. That is settling time in PSO method is $11 \mathrm{sec}$ and in $\mathrm{ZN}$ method is $18 \mathrm{sec}$.

Table: 6 Transient response specifications

\begin{tabular}{|c|c|c|}
\hline METHOD & Settling Time & Oscillations \\
\hline Z-N Method & $18 \mathrm{sec}$ & 9 \\
\hline PSO-PID & $11 \mathrm{sec}$ & 5 \\
\hline
\end{tabular}

\subsection{Simulation studies of a two area power system with multi -source power generation}

Simulation is carried out with $1 \%$ step load perturbation in area-1.For comparison the PID controller was tuned using conventional Ziegler-Nichols tuning rule based on critical gain $K_{u}$ and critical period $T_{u}$. Value of $K_{u}$ and $T_{u}$ were calculated from the sustained oscillations of the output by employing only proportional controller. The values obtained after simulation run in area- 1 are critical gain $\mathrm{K}_{\mathrm{u}}=3.965$ and critical period $\mathrm{T}_{\mathrm{u}}=1.375 \mathrm{sec}$ and in area- 2 are critical gain $\mathrm{K}_{\mathrm{u}}=3.3$ and critical period $\mathrm{T}_{\mathrm{u}}=1.5 \mathrm{sec}$. The minimum value of the $J$ is $6.599 * 10^{-5}$.

The MATLAB code based on PSO algorithm has been run in MATALB Environment. PSO parameters taken for optimizations are: Population size $=80$, Maximum number of iterations $=40, c 1=2 ; c 2=2$ and simulation time $=50 \mathrm{~s}$. The minimum value of the $J$ is $4.2047 * 10^{-5}$. The optimized controller gains obtained are shown in Table 7 .

Table: 7 Optimized values of PID controller parameters

\begin{tabular}{|c|c|c|c|c|}
\hline Method & Area & $\mathbf{K}_{\mathbf{P}}$ & $\mathbf{K}_{\mathbf{I}}$ & $\mathbf{K}_{\mathbf{D}}$ \\
\hline $\mathbf{Z}$ ZN & 1 & 2.379 & 0.6875 & 0.1718 \\
\cline { 2 - 5 } method & 2 & 1.98 & 0.75 & 0.1875 \\
\hline PSO & 1 & 3 & 0.8531 & 0.35 \\
\cline { 2 - 5 } method & 2 & 1.98 & 0.3919 & 0.1978 \\
\hline
\end{tabular}

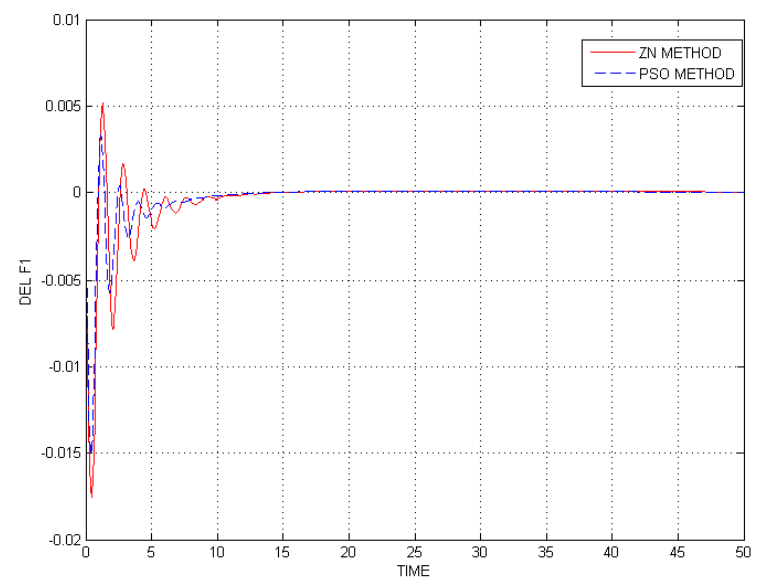

Figure.11 Frequency deviation in area-1 due to step change in area-1

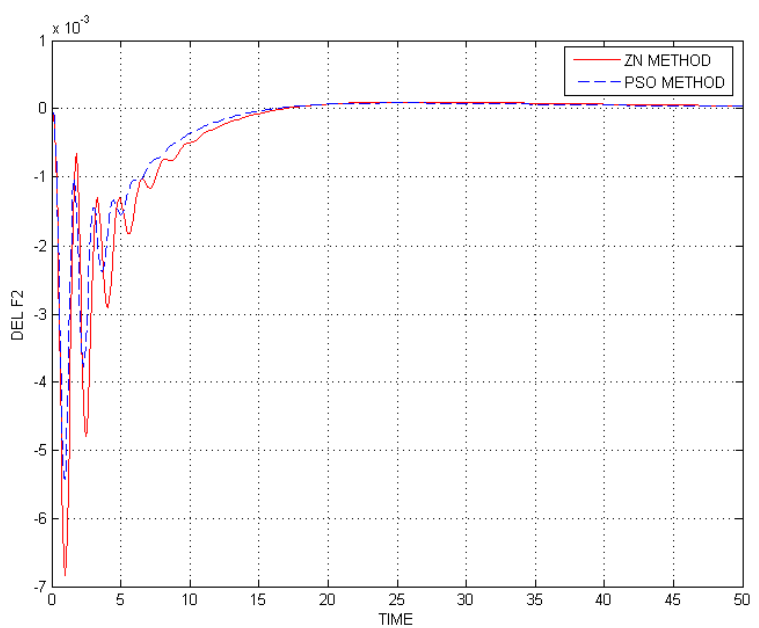

Figure.12 Frequency deviation in area-2 due to step change in area-1 


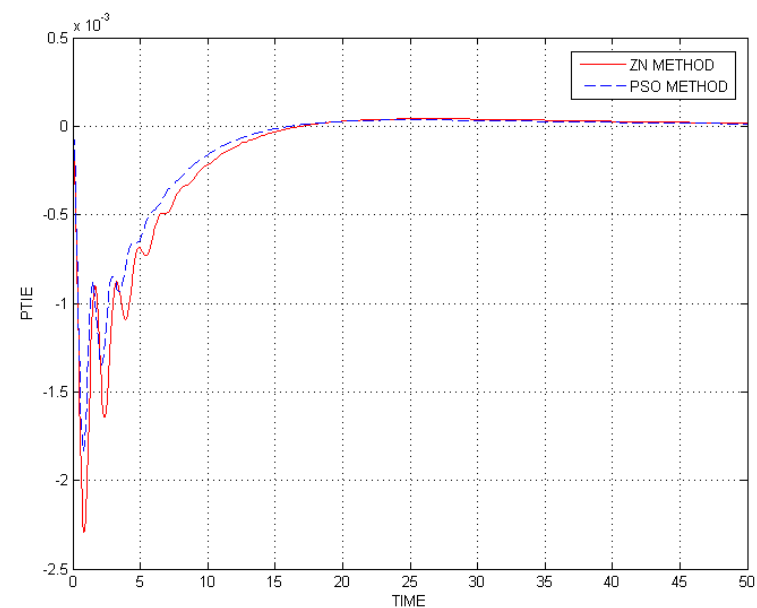

Figure.13 Tie line power deviation due to step change in area-1

The dynamic responses of a two area power system with multi sources are shown in the figures 11-13. The frequency deviation responses of control area-1 and area-2 are shown in figure 11 and 12, respectively. The tie-line power deviation is shown in figure 13. It was observed that compared with conventional (Z-N) method in PSO method number of oscillations reduces. It is observed that control frequency deviation in area-1and area- 2 and tie line power deviation settles quickly in PSO-PID method when compared with conventional (Z-N) method. That is settling time in PSO method is 12 and in $\mathrm{ZN}$ method is $14 \mathrm{sec}$.

Table: 8 Transient response specifications

\begin{tabular}{|c|c|c|}
\hline METHOD & Settling Time & Oscillations \\
\hline Z-N Method & $14 \mathrm{sec}$ & 5 \\
\hline PSO-PID & $12 \mathrm{sec}$ & 3 \\
\hline
\end{tabular}

\section{CONCLUSION}

In this paper, PSO based PID controller design has been proposed for an interconnected system. A two area thermal power system with governor dead band and a two area system with multi source power generation have been considered to demonstrate the proposed methodology. Simulation results prove that the designed PSO based PID controller gives very good transient and steady state performance for frequency and tie line power deviation compared to Zeigler-Nichols tuned PID controller. Area frequency deviations settle quickly and the dynamic responses are less oscillatory with low amplitude of peak over shoots. The tie line power deviation settles with zero steady state errors. The dynamic responses satisfy the LFC requirements. The PSO based PID controller is efficient to cope up the LFC problem. In this work only PSO algorithm is used to obtain the gain values of controllers for two-area interconnected systems. So it can be implemented for multi area power system. Other algorithms can also be considered to get the controller values and comparison can be made among the algorithms.

\section{REFERENCES}

[1] Ivan Zelinka, Pandian Vasant, Nader Barsoum "Power, Control and Optimization (Lecture Notes in Electrical Engineering) ”,Hardcover - Import, 23 May 2013.

[2] Majid Alizadeh Moghadam*, Saeed Jalilzadeh, "Control of AGC in Interconnected Power System with Diverse Sources of Power Generation", Universal Journal of Electrical and Electronic Engineering 2(7): 259-269, 2014.

[3] K. P. Singh Parmar, "PSO based PI Controller for the LFC System of an Interconnected Power System", International Journal of Computer Applications (0975 8887) Volume 88 - No.7, February 2014.

[4] A.Sharif, K.Sabahi, M.Aliyari Shoorehdeli, M.A.Nekoui, M.Teshnehlab, "Load Frequency Control in Interconnected power System Using Multi-objective PID Controller", 2008 IEEE Conference on Soft Computing in Industrial Applications (SMCia/08), June 25-27, 2008, Muroran, Japan

[5] Santigopal Pain, Parimal Acharjee, "Multiobjective Optimization of Load Frequency Control using PSO", International Journal of Emerging Technology and Advanced Engineering, Volume 4, Special Issue 7, April 2014.

[6] Ranuva Nageswara Rao, P.Rama Krishna Reddy “PSO based tuning of PID controller for a Load frequency control in two area power system" International Journal of Engineering Research and Applications (IJERA), Vol. 1, Issue 3, pp. 1499-1505.

[7] Elgerd OI. Electric energy system theory: an introduction. 2nd ed. New York: McGraw Hill; 1983.

[8] IEEE power engineering systems committee report. Dynamic models for steam and hydro turbines for power systems studies, IEEE Trans Power App Syst 1973; PAS92.

[9] IEEE power engineering systems committee report. Hydraulic turbine and turbine control models for system dynamics. IEEE Trans Power Syst 1992;PWRS-7.

[10] Working group on prime mover and energy supply models for system dynamic performance studies. Dynamic models for combined cycle plants in power system studies. IEEE Trans Power Syst 1994; 9(3):1698708 .

[11] P S R MURTY "Operation and Control in Power Systems".

[12] Ashok Mohan Jadhav, Dr.K.Vadirajacharya, "Performance Verification of PID Controller in an Interconnected Power System Using Particle Swarm Optimization". 2nd International Conference on Advances in Energy Engineering (ICAEE2011).

[13] K.Ogata, "Modern Control Engineering", Prentice Hall Of India, New Delhi, 2000. 